\title{
Anxiety and depression in patients with endometriosis: impact and management challenges
}

\author{
This article was published in the following Dove Press journal: \\ International Journal of Women's Health \\ 16 May 2017 \\ Number of times this article has been viewed
}

\author{
Antonio Simone Laganà' \\ Valentina Lucia La Rosa ${ }^{2}$ \\ Agnese Maria Chiara \\ Rapisarda ${ }^{3}$ \\ Gaetano Valenti ${ }^{3}$ \\ Fabrizio Sapia ${ }^{3}$ \\ Benito Chiofalo' \\ Diego Rossetti ${ }^{4}$ \\ Helena Ban Frangež ${ }^{5}$ \\ Eda Vrtačnik Bokal ${ }^{5}$ \\ Salvatore Giovanni Vitale' \\ 'Unit of Gynecology and Obstetrics, \\ Department of Human Pathology \\ in Adulthood and Childhood \\ "G Barresi", University of Messina, \\ Messina, ${ }^{2}$ Unit of Psychodiagnostics \\ and Clinical Psychology, ${ }^{3}$ Department \\ of General Surgery and Medical \\ Surgical Specialties, University of \\ Catania, Catania, ${ }^{4}$ Department of \\ Maternal and Child Health, Gavardo \\ Hospital, Brescia, Italy; ${ }^{5}$ Department \\ of Reproduction, University Medical \\ Center Ljubljana, Ljubljana, Slovenia
}

Correspondence: Antonio Simone Laganà Unit of Gynecology and Obstetrics, Department of Human Pathology in Adulthood and Childhood "G Barresi", University of Messina, Via C Valeria I, 98125 Messina, Italy

$\mathrm{Tel}+390902212183$

Fax +39090 2937083

Email antlagana@unime.it

\begin{abstract}
Endometriosis is one of the most common gynecological diseases and affects $\sim 10 \%$ of women in reproductive age. The most common clinical signs of endometriosis are menstrual irregularities, chronic pelvic pain (CPP), dysmenorrhea, dyspareunia and infertility. Symptoms of endometriosis often affect psychological and social functioning of patients. For this reason, endometriosis is considered as a disabling condition that may significantly compromise social relationships, sexuality and mental health. Considering this point, the aim of this narrative review is to elucidate the impact of anxiety and depression in the management of women with endometriosis. Psychological factors have an important role in determining the severity of symptoms, and women who suffer from endometriosis report high levels of anxiety, depression and other psychiatric disorders. In addition, endometriosis is one of the most important causes of CPP; women with endometriosis suffer from a wide range of pelvic pain such as dysmenorrhea, dyspareunia, nonmenstrual (chronic) pelvic pain, pain at ovulation, dyschezia and dysuria. Several studies have underlined the influence of CPP on quality of life and psychological well-being of women with endometriosis. Data suggest that the experience of pelvic pain is an important component of endometriosis and may significantly affect emotive functioning of affected women. It has been demonstrated that high levels of anxiety and depression can amplify the severity of pain. Further studies are needed to better understand the relationship between psychological factors and perception of pain. Treatment of endometriosis may be hormonal or surgical. Surgery is the primary treatment for more severe forms of endometriosis. There are few data in the literature about the influence of psychological factors and psychiatric comorbidities on the effectiveness of treatments. It is important to evaluate the presence of previous psychiatric diseases in order to select the most appropriate treatment for the patient.
\end{abstract}

Keywords: endometriosis, pelvic pain, anxiety, depression

\section{Introduction}

Endometriosis is one of the most common gynecological diseases and is defined as a benign and proliferative chronic disorder characterized by the ectopic presence and growth of functional endometrial tissue, glands and stroma, outside the uterine cavity. ${ }^{1-4}$ Endometriosis affects $\sim 10 \%$ of women in reproductive age and up to $50 \%$ of infertile women. ${ }^{4-8}$ According to the classification of the American Society for Reproductive Medicine, there are four different stages of endometriosis; stages I and II represent initial stages, while stages III and IV are advanced stages. ${ }^{9}$ The stage of endometriosis is based on the location, amount, depth and size of the endometriotic foci. Specific criteria are the extent of the spread of the tissue, the involvement of pelvic structures, the extent of pelvic adhesions and the obstruction of the fallopian tubes. ${ }^{9,10}$ The stage of endometriosis does not necessarily correspond to the severity of symptoms, and hence a woman in stage I may experience very intense symptoms, 
while a woman in stages II-III may have less intense symptoms and signs. ${ }^{9}$ The pathogenesis of the disease is not fully known, and several theories have been proposed to explain it. The most accepted theory suggests that immune dysfunction and abnormal differentiation of endometriotic tissue may be involved in the development of the disease. ${ }^{3}$ Other possible explanatory hypotheses include genetic, epigenetic or environmental factors. ${ }^{2,3,11,12}$ Moreover, the embryogenetic theory and the potential role of endocrine disruptors are other hypotheses considered to be plausible regarding the pathogenesis of endometriosis. ${ }^{13-15}$ The diagnosis of endometriosis is traditionally based on laparoscopic inspection of the pelvis and should ideally be confirmed by histological examination of the excised lesions. ${ }^{7,16}$ The most common clinical signs of endometriosis are menstrual irregularities, chronic pelvic pain (CPP), dysmenorrhea, dyspareunia and infertility. ${ }^{4}$ A significant proportion of women with endometriosis are asymptomatic, and the disease is often diagnosed during laparoscopic investigation due to other pelvic conditions. ${ }^{17,18}$ Three different clinical presentations of endometriosis have been described, peritoneal endometriosis, endometriotic ovarian cysts and deeply infiltrating endometriosis (DIE). ${ }^{4}$ DIE is the most aggressive presentation of endometriosis; it is characterized by an infiltration of $>5 \mathrm{~mm}$ of endometrial tissue into the retroperitoneal space and accounts for $\sim 20 \%$ of the cases. ${ }^{4,19,20}$ Symptoms of endometriosis can often affect psychological and social functioning of patients. $^{21,22}$ For this reason, endometriosis is considered as a disabling condition that may significantly compromise social relationships, sexuality and mental health. ${ }^{22-24}$ Although the impact of endometriosis on mental health and psychological well-being has been investigated in several studies, data published so far are not robust enough to draw firm conclusion. Therefore, the aim of this narrative review is to elucidate the impact of anxiety and depression in the management of women with endometriosis.

\section{Anxiety and depressive symptoms in women with endometriosis}

As detailed below, several studies have reported the association between endometriosis and psychological diseases. Pope et $\mathrm{al}^{25}$ underlined that endometriosis is related to a wide range of psychiatric symptoms, especially depression, anxiety, psychosocial stress and a poor quality of life. According to recent literature, ${ }^{21,23,25-31}$ depression and anxiety are the most common disorders associated with endometriosis. In this context, Low et $\mathrm{al}^{32}$ investigated the possibility of a specific psychological profile associated with endometriosis. A total of 81 women with pelvic pain were studied, of whom 40 had endometriosis and 41 had other gynecological problems. Each patient completed six standardized psychometric tests (Eysenck Personality Questionnaire [EPQ], Beck Depression Inventory [BDI], General Health Questionnaire, State-Trait Anxiety Inventory [STAI], The Golombok Rust Inventory of Marital State and The Short-Form McGill Pain Questionnaire) to assess personality, psychopathology, marital state and pain. According to the results of their study, endometriosis patients showed higher psychoticism, introversion and anxiety scores than those of women with other gynecological conditions. In addition, a study by Laganà et $\mathrm{al}^{30}$ investigated quality of life, negative emotions, such as anger, anxiety and depression, and possible psychopathological comorbidity in a sample of 166 women with endometriosis. Patients completed the following self-report instruments: Symptom Checklist-90-R, State-Trait Anger Expression Inventory-2, Self-Rating Anxiety Scale, Self-Rating Depression Scale and Quality of Life Index. The results showed that somatization, depression, sensitivity and phobic anxiety are higher in these patients than in women without endometriosis. ${ }^{30}$ Moreover, the same authors found that women with endometriosis are characterized by high levels of anxiety and a significant decline in quality of life. Chen et $\mathrm{al}^{28}$ used the Taiwan National Health Insurance Research Database (NHIRD) with a longitudinal study design to identify women with endometriosis who were diagnosed with depression or anxiety disorders by board-certified psychiatrists. They found that endometriosis is associated with an elevated risk of developing depression and anxiety disorders. ${ }^{28,29}$

In full agreement with these data, Sepulcri Rde and do Amaral $^{33}$ evaluated depressive symptoms, anxiety and quality of life in 104 women with a diagnosis of pelvic endometriosis. The BDI and the Hamilton Rating Scale for Depression (HAM-D) were used to evaluate depressive symptoms; the Spielberger STAI and the Hamilton Rating Scale for Anxiety (HAM-A) to evaluate anxiety symptoms, and the short (26-item) version of the World Health Organization Quality of Life Assessment-BREF (WHOQOL-BREF) to evaluate quality of life. They found that $86.5 \%$ presented depressive symptoms and $87.5 \%$ presented anxiety and, most important, that psychiatric symptoms were not associated with endometriosis stage. ${ }^{33}$ In this study, age correlated positively with depressive symptoms, while there was no association between age and anxiety symptoms. ${ }^{25,33}$ Nevertheless, other authors found that only $29 \%$ of endometriotic women showed moderate to severe anxiety symptoms, while depression was present in $14.5 \% .^{21}$ 
These apparently contradictory results may be due at least in part to different methodologies used to identify psychiatric symptoms or to selection biases (in particular, the inclusion of other comorbidities that can severely influence mental health). In addition, endometriotic patients show high levels of alexithymia, ${ }^{31}$ which further makes it difficult to identify other psychiatric disturbances, due to a severe difficulty in identifying and describing emotions. All the relevant information about the reported studies are summarized in Table 1.

Briefly, the literature confirms a significant incidence of anxiety, depression and psychopathological symptoms among women with endometriosis. These comorbidities could influence the severity of symptoms and the healthrelated quality of life of affected women. ${ }^{21-23,33}$

\section{The relation between endometriosis, pelvic pain and psychological diseases}

The presence of CPP is an important variable to be taken into account when assessing the association between endometriosis and psychological diseases. CPP is defined as a nonmalignant pain perceived in pelvic areas that is constant or recurs over a period of 6 months. ${ }^{34}$ Endometriosis is one of the most common causes of CPP ;5,36 indeed, women with endometriosis may suffer from a wide range of pelvic pain such as dysmenorrhea, dyspareunia, nonmenstrual (chronic) pelvic pain, pain at ovulation, dyschezia and dysuria. ${ }^{18,31,35}$ It is important to underline that pain seems to be independent of the stage of endometriosis, so women with mild endometriosis may have intense pelvic pain while women with more severe endometriosis may suffer less from acute/chronic pain..$^{31,37-39}$ This finding suggests that psychological factors may be involved, which influence pain experience in women with endometriosis. ${ }^{31,37,39}$ It has been demonstrated that pelvic pain has significant negative effects on women's mental health and quality of life; in particular, women who suffer from pelvic pain report high levels of anxiety and depression, loss of working ability, limitations in social activities and a poor quality of life. ${ }^{39-46}$ Several studies have tried to investigate the relationship between endometriosis, pelvic pain and depression or anxiety disorders. Lorençatto et $\mathrm{al}^{42}$ compared the prevalence of depression between a group of women with a diagnosis of endometriosis and CPP and a group of women with endometriosis but no CPP. The presence and degree of depression were evaluated by using the BDI. The results of this study show that depression was present in $86 \%$ of the women with
$\mathrm{CPP}$ and in $38 \%$ of the women without pain. Moreover, the symptoms associated with depression (somatic concerns, work inhibition, dissatisfaction and sadness) were significantly higher in women with pain. According to these data, depression may be the result of the experience of pelvic pain rather than of endometriosis itself. This hypothesis seems to be confirmed by the study performed by Souza et al, ${ }^{44}$ in which 57 patients aged between 25 and 48 years who underwent laparoscopy because of CPP were evaluated for quality of life and depressive symptoms. The WHOQOLBREF was used to evaluate quality of life while the HAM-A and the BDI were used to investigate the presence of anxiety and depressive symptoms. According to their data analysis, CPP was correlated with lower quality of life and higher psychological disease. However, endometriosis in addition to CPP did not have an additional impact upon the quality of life..$^{44}$ In this regard, Roth et a ${ }^{47}$ compared women suffering from CPP associated with endometriosis with women experiencing CPP due to other medical conditions. Participants completed a battery of validated questionnaires assessing demographic status, pain experience and other pain-related symptoms, pain disability, frequency of depressive symptoms, level of affective distress, satisfaction with pain treatment and satisfaction with their marital relationship. Interestingly, they did not find significant differences between the two groups for frequency of depressive symptoms and level of affective distress. Nevertheless, large cohort analyses $^{37}$ found that women with endometriosis associated with pelvic pain reported higher levels of anxiety and depression and lower quality of life than women without pain symptoms, and healthy women. Although current data do not allow to draw firm conclusions, accumulating evidence suggests that psychopathological diseases might amplify pain symptoms in endometriotic patients ${ }^{31}$ and, in this way, contribute to create a vicious circle (psychopathological diseases $\rightarrow$ increased CPP $\rightarrow$ worsening of psychopathological diseases; Figure 1).

Summarizing the results of the abovementioned studies (Table 1), the experience of CPP should be considered as an important component of having endometriosis and may significantly affect women's quality of life and psychological well-being. More specifically, psychiatric comorbidities associated with endometriosis seem to be an effect of the experience of pelvic pain rather than of endometriosis itself. ${ }^{25,47}$ The relationship between emotional diseases and perception of pain in women with endometriosis is still unclear. Studies on this topic have obtained controversial results; it has not yet been elucidated if depression, anxiety and emotional 


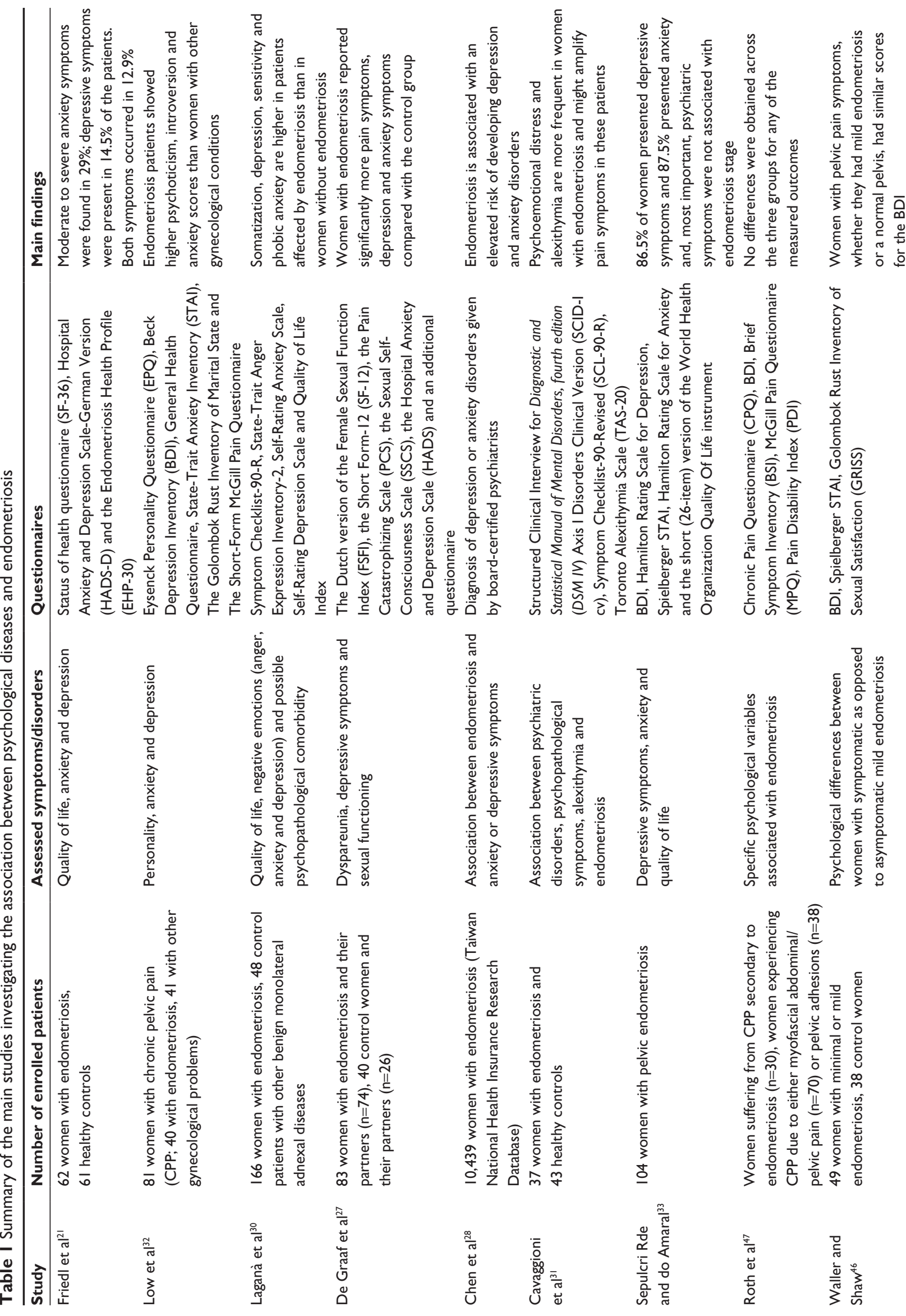



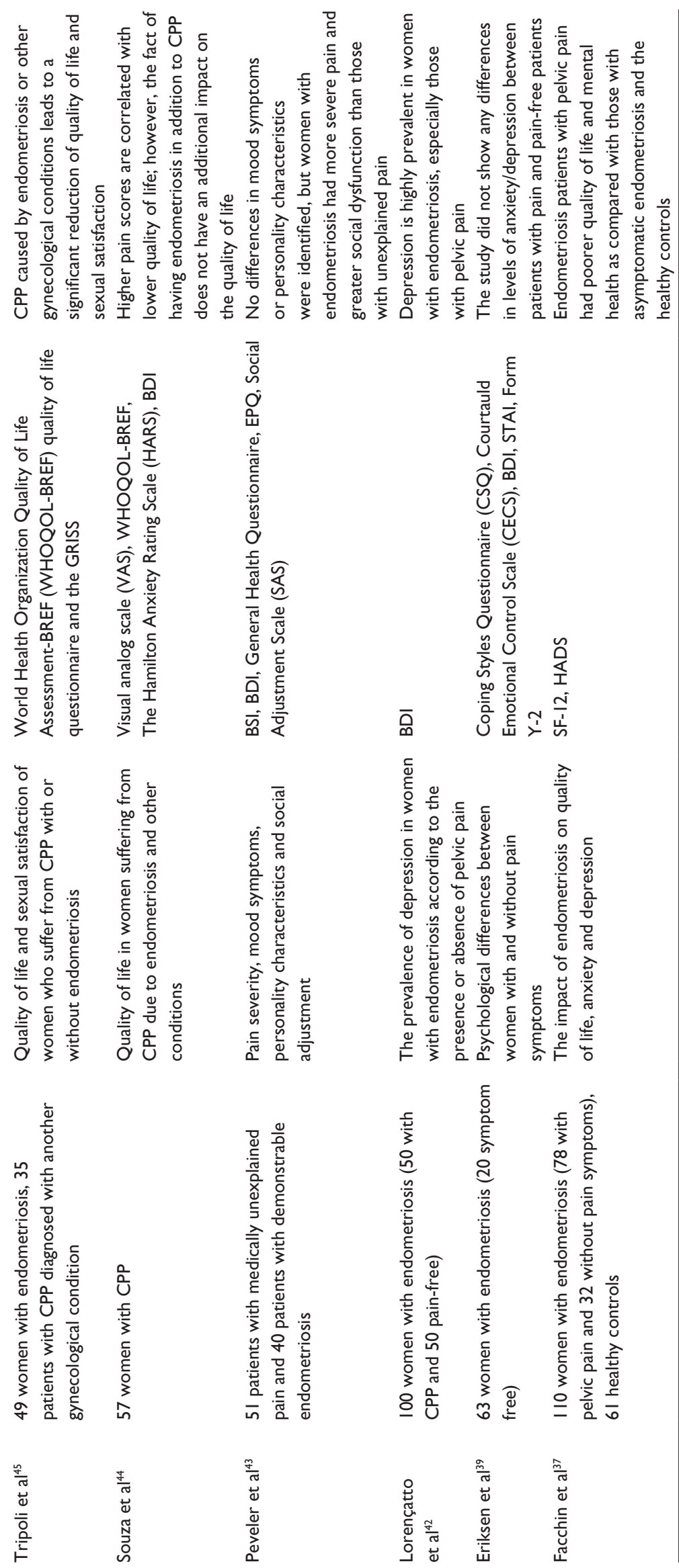

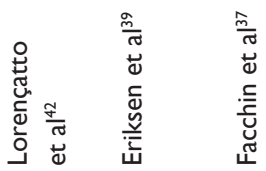




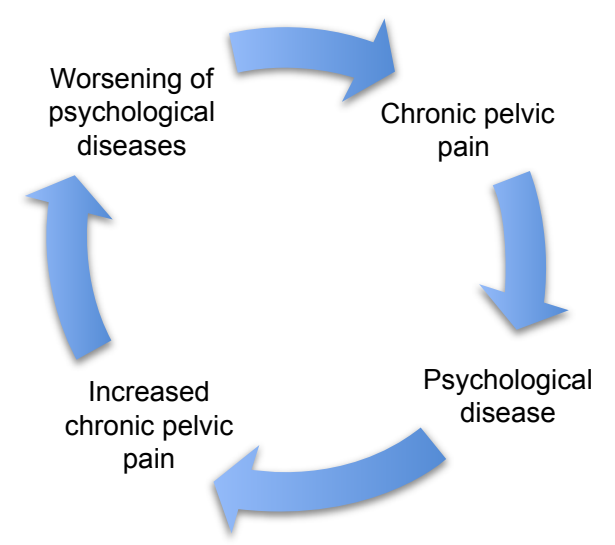

Figure I The vicious circle of chronic pelvic pain and psychological diseases.

distress determine an increased perception of pain or if pain causes psychological distress and psychopathological symptoms. ${ }^{31,33,42}$ However, anxiety and depression could increase pain perception both emotionally and cognitively, determining less tolerance to pain and greater sensitivity to physical sensations in general. ${ }^{33}$ Consequently, further studies are needed to investigate these aspects.

\section{Treatment of endometriosis and psychological effects}

Treatment of endometriosis can be complex and it is important to take into account several factors such as side effects, the anatomic type of endometriosis, role of previous surgery, infertility and future fertility desires. ${ }^{7,48}$ The main purpose of treatments should be pain control, improvement of the quality of life, prevention of disease recurrence, fertility preservation and reduction of anatomical damage. ${ }^{48,49}$ Hormonal treatment aims at downregulation of the ovaries, reducing the estrogen stimulation of endometriotic growth. ${ }^{7,48-50}$ The choice of the most appropriate hormonal therapy depends on several factors such as therapeutic effectiveness, tolerability, drug cost, physician's experience and expected patient compliance. ${ }^{48}$ Combined oral contraceptives (COCs), danazol, gestrinone, medroxyprogesterone acetate and gonadotropin-releasing hormone $(\mathrm{GnRH})$ agonists are the most frequently used drugs in the hormonal treatment of endometriosis. ${ }^{49,50}$ During the last few years, GnRH agonists, which downregulate the pituitary and thereby indirectly the ovaries, have been commonly used as alternatives to gestagens and danazol in order to avoid a high rate of side effects such as weight gain, acne and headache. ${ }^{49-52}$ Although the GnRH agonists are effective in reducing endometriosis symptoms, they are often associated with anxiety and depression during treatment. ${ }^{25,49,52,53}$ For this reason, psychiatric drugs may be considered as adjunctive treatment during endometriosis therapy, even if they can produce side effects and some patients are reluctant to take additional drugs. ${ }^{25,49}$ There are few studies in the literature about the effects of hormonal treatment for endometriosis on quality of life and psychological functioning of affected women: Bergqvist and Theorell ${ }^{50}$ evaluated quality of life and psychiatric comorbidities in a sample of 48 women with endometriosis before, during, and after treatment with nafarelin or medroxyprogesterone acetate, using questionnaires that were both of a general and a more specific nature. They found that there was a significant reduction of symptoms during the study and important factors for quality of life such as sleep disturbances, anxiety and depression symptoms improved significantly after hormonal treatment. ${ }^{50}$ In partial agreement with the previous study, Zhao et a $l^{49}$ investigated the impact of progressive muscle relaxation (PMR) training on anxiety, depression and quality of life of patients with endometriosis undergoing GnRH agonist therapy. The patients were evaluated with STAI, Hospital Anxiety and Depression Scale Depression subtest (HADS-D) and SF-36 before and after the PMR intervention. According to the results of this study, PMR training is effective in reducing anxiety and depressive symptoms, which could be associated with GnRH agonist therapy. However, it is important to evaluate previous psychiatric comorbidities that could increase the risk for psychiatric disturbance related to hormonal therapy for endometriosis. ${ }^{25}$

Surgery is the primary treatment for more severe forms of endometriosis, such as DIE. ${ }^{4,54,55}$ Currently, several gynecological surgeons are attempting to modulate how much their surgery is radical according to fertility desires and future quality of life of the patient. To date, there are few data available in the literature on quality of life and anxiety and depression levels after surgery for endometriosis. A review by Deguara et al ${ }^{54}$ underlined that laparoscopic surgery is associated with improved quality of life and emotional well-being compared to medical therapies. A prospective cohort study by Van den Broeck et a ${ }^{55}$ evaluated depression levels, relationship satisfaction and sexual functioning of 203 women who underwent laparoscopic surgery for moderate or severe endometriosis. Participating patients completed the BDI, Dyadic Adjustment Scale (DAS) and the Short Sexual Functioning Scale (SSFS) 1 month prior to and 6, 12, 18 and 24 months after the intervention. Results showed that radical surgery for endometriosis improved the levels of depression and sexual functioning of the patients. ${ }^{55}$ These data suggest the importance of psychological factors not only for the severity of symptoms but also in the management of the disease and in the selection of the most appropriate therapy. 
Considering this scenario, we take the opportunity to solicit further studies to clarify the relationship between endometriosis therapies and psychological outcomes, taking into account other endometriosis-associated comorbidities such as infertility. ${ }^{56,57}$ In particular, it would be interesting to investigate whether a correlation occurs between psychological outcomes and levels of pro-inflammatory cytokines in peritoneal fluid, ${ }^{58-60}$ which are known to play a detrimental role in pain exacerbation ${ }^{61}$ and may contribute to endometriosis-related infertility. ${ }^{62}$

\section{Conclusion}

Endometriosis is a very complex condition and psychological factors have an important role in determining the severity of symptoms and the effectiveness of the treatments. According to recent data, women with endometriosis are at risk for anxiety, depressive symptoms and other psychiatric disorders. Since it is still unclear if these comorbidities are a result of endometriosis itself or other factors such as CPP, we solicit further studies about this topic in order to better understand the relationship between endometriosis and psychological diseases. In addition, we take the opportunity to stress the importance of a multidisciplinary approach in the management of women with endometriosis. In this regard, psychological assessment is recommended in order to identify women at risk of developing symptoms of anxiety and depression and provide them an adequate psychological support. The aim should be to reduce as much as possible the impact of endometriosis on quality of life and psychological well-being of these patients.

\section{Disclosure}

The authors report no conflicts of interest in this work.

\section{References}

1. Greene AD, Lang SA, Kendziorski JA, Sroga-Rios JM, Herzog TJ, Burns KA. Endometriosis: where are we and where are we going? Reproduction. 2016;152(3):R63-R78.

2. Giudice LC, Kao LC. Endometriosis. Lancet. 2004;364(9447): 1789-1799.

3. Leyland N, Casper R, Laberge P, Singh SS; SOGC. Endometriosis: diagnosis and management. J Obstet Gynaecol Can. 2010;32(7 suppl 2): $\mathrm{S} 1-\mathrm{S} 32$.

4. Laganà AS, Vitale SG, Trovato MA, et al. Full-thickness excision versus shaving by laparoscopy for intestinal deep infiltrating endometriosis: rationale and potential treatment options. Biomed Res Int. 2016;2016: 3617179.

5. Laganà AS, Salmeri FM, Triolo O, Vitale SG, Granese R, Sofo V. Comments on "rhTNFR:Fc suppresses the development of endometriosis in a mouse model by downregulating cell proliferation and invasiveness". Reprod Sci. Epub 2016 Jul 28.

6. Viganò P, Parazzini F, Somigliana E, Vercellini P. Endometriosis: epidemiology and aetiological factors. Best Pract Res Clin Obstet Gynaecol. 2004;18(2):177-200.
7. Dunselman GA, Vermeulen N, Becker C, et al; European Society of Human Reproduction and Embryology. ESHRE guideline: management of women with endometriosis. Hum Reprod. 2014;29(3):400-412.

8. Bulletti C, Coccia ME, Battistoni S, Borini A. Endometriosis and infertility. J Assist Reprod Genet. 2010;27(8):441-447.

9. Revised American Society for Reproductive Medicine classification of endometriosis: 1996. Fertil Steril. 1997;67(5):817-821.

10. Haas D, Shebl O, Shamiyeh A, Oppelt P. The rASRM score and the Enzian classification for endometriosis: their strengths and weaknesses. Acta Obstet Gynecol Scand. 2013;92(1):3-7.

11. Cramer DW, Missmer SA. The epidemiology of endometriosis. Ann N Y Acad Sci. 2002;955:11-22.

12. Parazzini F, Cipriani S, Bravi F, et al. A metaanalysis on alcohol consumption and risk of endometriosis. Am J Obstet Gynecol. 2013; 209(2):106.e1-106.e10.

13. Signorile PG, Baldi F, Bussani R, et al. Embryologic origin of endometriosis: analysis of 101 human female fetuses. J Cell Physiol. 2012; 227(4):1653-1656.

14. Bouquet de Jolinière J, Ayoubi JM, Lesec G, et al. Identification of displaced endometrial glands and embryonic duct remnants in female fetal reproductive tract: possible pathogenetic role in endometriotic and pelvic neoplastic processes. Front Physiol. 2012;3:444.

15. Signorile PG, Spugnini EP, Mita L, et al. Pre-natal exposure of mice to bisphenol A elicits an endometriosis-like phenotype in female offspring. Gen Comp Endocrinol. 2010;168(3):318-325.

16. Kennedy S, Bergqvist A, Chapron C, et al; ESHRE Special Interest Group for Endometriosis and Endometrium Guideline Development Group. ESHRE guideline for the diagnosis and treatment of endometriosis. Hum Reprod. 2005;20(10):2698-2704.

17. Wolthuis AM, Tomassetti C. Multidisciplinary laparoscopic treatment for bowel endometriosis. Best Pract Res Clin Gastroenterol. 2014; 28(1):53-67.

18. Triolo $\mathrm{O}$, Laganà AS, Sturlese E. Chronic pelvic pain in endometriosis: an overview. J Clin Med Res. 2013;5(3):153-163.

19. Boileau L, Laporte S, Bourgaux JF, et al. [Laparoscopic colorectal resection for deep pelvic endometriosis: evaluation of post-operative outcome]. J Gynecol Obstet Biol Reprod (Paris). 2012;41(2):128-135.

20. Chopin N, Vieira M, Borghese B, et al. Operative management of deeply infiltrating endometriosis: results on pelvic pain symptoms according to a surgical classification. J Minim Invasive Gynecol. 2005;12(2): $106-112$.

21. Friedl F, Riedl D, Fessler S, et al. Impact of endometriosis on quality of life, anxiety, and depression: an Austrian perspective. Arch Gynecol Obstet. 2015;292(6):1393-1399.

22. Jia SZ, Leng JH, Shi JH, Sun PR, Lang JH. Health-related quality of life in women with endometriosis: a systematic review. J Ovarian Res. 2012;5(1):29.

23. Vitale SG, La Rosa VL, Rapisarda AM, Laganà AS. Impact of endometriosis on quality of life and psychological well-being. J Psychosom Obstet Gynaecol. Epub 2016 Oct 18:1-3.

24. Siedentopf F, Tariverdian N, Rücke M, Kentenich H, Arck PC. Immune status, psychosocial distress and reduced quality of life in infertile patients with endometriosis. Am J Reprod Immunol. 2008;60(5):449-461.

25. Pope CJ, Sharma V, Sharma S, Mazmanian D. A systematic review of the association between psychiatric disturbances and endometriosis. J Obstet Gynaecol Can. 2015;37(11):1006-1015.

26. Vitale SG, Petrosino B, La Rosa VL, Rapisarda AM, Laganà AS. A systematic review of the association between psychiatric disturbances and endometriosis. J Obstet Gynaecol Can. 2016;38(12):1079-1080.

27. De Graaff AA, Van Lankveld J, Smits LJ, Van Beek JJ, Dunselman GA. Dyspareunia and depressive symptoms are associated with impaired sexual functioning in women with endometriosis, whereas sexual functioning in their male partners is not affected. Hum Reprod. 2016; 31(11):2577-2586.

28. Chen LC, Hsu JW, Huang KL, et al. Risk of developing major depression and anxiety disorders among women with endometriosis: a longitudinal follow-up study. J Affect Disord. 2016;190:282-285. 
29. Laganà AS, La Rosa V, Petrosino B, Vitale SG. Comment on "Risk of developing major depression and anxiety disorders among women with endometriosis: A longitudinal follow-up study". J Affect Disord. 2017;208:672-673.

30. Laganà AS, Condemi I, Retto G, et al. Analysis of psychopathological comorbidity behind the common symptoms and signs of endometriosis. Eur J Obstet Gynecol Reprod Biol. 2015;194:30-33.

31. Cavaggioni G, Lia C, Resta S, et al. Are mood and anxiety disorders and alexithymia associated with endometriosis? A preliminary study. Biomed Res Int. 2014;2014:786830.

32. Low WY, Edelmann RJ, Sutton C. A psychological profile of endometriosis patients in comparison to patients with pelvic pain of other origins. J Psychosom Res. 1993;37(2):111-116.

33. Sepulcri Rde P, do Amaral VF. Depressive symptoms, anxiety, and quality of life in women with pelvic endometriosis. Eur J Obstet Gynecol Reprod Biol. 2009;142(1):53-56.

34. Fall M, Baranowski AP, Fowler CJ, et al; European Association of Urology. EAU guidelines on chronic pelvic pain. Eur Urol. 2004;46(6): 681-689.

35. Porpora MG, Koninckx PR, Piazze J, Natili M, Colagrande S, Cosmi EV. Correlation between endometriosis and pelvic pain. J Am Assoc Gynecol Laparosc. 1999;6(4):429-434.

36. Hurd WW. Criteria that indicate endometriosis is the cause of chronic pelvic pain. Obstet Gynecol. 1998;92(6):1029-1032.

37. Facchin F, Barbara G, Saita E, et al. Impact of endometriosis on quality of life and mental health: pelvic pain makes the difference. J Psychosom Obstet Gynaecol. 2015;36(4):135-141.

38. Vitale SG, La Rosa VL, Rapisarda AM, Laganà AS. Comment on: "Impact of endometriosis on quality of life and mental health: pelvic pain makes the difference". J Psychosom Obstet Gynaecol. 2017;38(1): 81-82.

39. Eriksen HL, Gunnersen KF, Sørensen JA, Munk T, Nielsen T, Knudsen UB. Psychological aspects of endometriosis: differences between patients with or without pain on four psychological variables. Eur J Obstet Gynecol Reprod Biol. 2008;139(1):100-105.

40. Cox H, Henderson L, Andersen N, Cagliarini G, Ski C. Focus group study of endometriosis: struggle, loss and the medical merry-go-round. Int J Nurs Pract. 2003;9(1):2-9.

41. Kumar A, Gupta V, Maurya A. Mental health and quality of life of chronic pelvic pain and endometriosis patients. J Proj Psychol Ment Health. 2010;17(2):153-157.

42. Lorençatto C, Petta CA, Navarro MJ, Bahamondes L, Matos A. Depression in women with endometriosis with and without chronic pelvic pain. Acta Obstet Gynecol Scand. 2006;85(1):88-92.

43. Peveler R, Edwards J, Daddow J, Thomas E. Psychosocial factors and chronic pelvic pain: a comparison of women with endometriosis and with unexplained pain. J Psychosom Res. 1996;40(3):305-315.

44. Souza CA, Oliveira LM, Scheffel C, et al. Quality of life associated to chronic pelvic pain is independent of endometriosis diagnosis - a cross-sectional survey. Health Qual Life Outcomes. 2011;9:41.

45. Tripoli TM, Sato H, Sartori MG, de Araujo FF, Girão MJ, Schor E. Evaluation of quality of life and sexual satisfaction in women suffering from chronic pelvic pain with or without endometriosis. J Sex Med. 2011;8(2):497-503.

46. Waller KG, Shaw RW. Endometriosis, pelvic pain, and psychological functioning. Fertil Steril. 1995;63(4):796-800.
47. Roth RS, Punch M, Bachman JE. Psychological factors in chronic pelvic pain due to endometriosis: a comparative study. Gynecol Obstet Invest. 2011;72(1):15-19.

48. Bedaiwy MA, Allaire C, Yong P, Alfaraj S. Medical management of endometriosis in patients with chronic pelvic pain. Semin Reprod Med. 2017;35(1):38-53.

49. Zhao L, Wu H, Zhou X, Wang Q, Zhu W, Chen J. Effects of progressive muscular relaxation training on anxiety, depression and quality of life of endometriosis patients under gonadotrophin-releasing hormone agonist therapy. Eur J Obstet Gynecol Reprod Biol. 2012;162(2):211-215.

50. Bergqvist A, Theorell T. Changes in quality of life after hormonal treatment of endometriosis. Acta Obstet Gynecol Scand. 2001;80(7): 628-637.

51. Vercellini P, Cortesi I, Crosignani PG. Progestins for symptomatic endometriosis: a critical analysis of the evidence. Fertil Steril. 1997; 68(3):393-401.

52. Bergqvist A. Current drug therapy recommendations for the treatment of endometriosis. Drugs. 1999;58(1):39-50.

53. Brown J, Pan A, Hart RJ. Gonadotrophin-releasing hormone analogues for pain associated with endometriosis. Cochrane Database Syst Rev. 2010;(12):CD008475.

54. Deguara CS, Pepas L, Davis C. Does minimally invasive surgery for endometriosis improve pelvic symptoms and quality of life? Curr Opin Obstet Gynecol. 2012;24(4):241-244.

55. Van den Broeck U, Meuleman C, Tomassetti C, et al. Effect of laparoscopic surgery for moderate and severe endometriosis on depression, relationship satisfaction and sexual functioning: comparison of patients with and without bowel resection. Hum Reprod. 2013; 28(9):2389-2397.

56. Vitale SG, La Rosa VL, Rapisarda AM, Laganà AS. Psychology of infertility and assisted reproductive treatment: the Italian situation. J Psychosom Obstet Gynaecol. 2017;38(1):1-3.

57. Vitale SG, Petrosino B, La Rosa VL, Laganà AS. Comment on "Differences in psychophysical well-being and signs of depression in couples undergoing their first consultation for assisted reproduction technology (ART): an Italian pilot study". Eur J Obstet Gynecol Reprod Biol. 2017;211:210-211.

58. Vetvicka V, Laganà AS, Salmeri FM, et al. Regulation of apoptotic pathways during endometriosis: from the molecular basis to the future perspectives. Arch Gynecol Obstet. 2016;294(5):897-904.

59. Maniglio $\mathrm{P}$, Ricciardi E, Laganà AS, Triolo O, Caserta D. Epigenetic modifications of primordial reproductive tract: a common etiologic pathway for Mayer-Rokitansky-Kuster-Hauser Syndrome and endometriosis? Med Hypotheses. 2016;90:4-5.

60. Laganà AS, Triolo O, Salmeri FM, et al. Natural Killer T cell subsets in eutopic and ectopic endometrium: a fresh look to a busy corner. Arch Gynecol Obstet. 2016;293(5):941-949.

61. McKinnon B, Bersinger NA, Wotzkow C, Mueller MD. Endometriosisassociated nerve fibers, peritoneal fluid cytokine concentrations, and pain in endometriotic lesions from different locations. Fertil Steril. 2012;97(2):373-380.

62. Vassiliadis S, Relakis K, Papageorgiou A, Athanassakis I. Endometriosis and infertility: a multi-cytokine imbalance versus ovulation, fertilization and early embryo development. Clin Dev Immunol. 2005; 12(2):125-129.

\section{Dovepress}

\section{Publish your work in this journal}

The International Journal of Women's Health is an international, peerreviewed open-access journal publishing original research, reports, editorials, reviews and commentaries on all aspects of women's healthcare including gynecology, obstetrics, and breast cancer. The manuscript management system is completely online and includes

a very quick and fair peer-review system, which is all easy to use. Visit http://www.dovepress.com/testimonials.php to read real quotes from published authors. 